\title{
Synthesis, Microstructural Characterization and Microhardness of AlCoNi-SiC Composite Prepared by Mechanical Alloying
}

\author{
Francisco J Baldenebro-López $z^{a, b *}$, Hector Camacho-Montes ${ }^{a}$, Audel Santos-Beltrán ${ }^{c}$, M. Cristina \\ Maldonado-Orozco ${ }^{d, e}$, Cynthia D Gómez-Esparza a ${ }^{a}$ Roberto Martínez-Sánchez ${ }^{e}$ \\ ${ }^{a}$ Instituto de Ingeniería y Tecnología, Universidad Autónoma de Ciudad Juárez - UACJ, Av. Del \\ Charro, 610, Norte Cd, Juárez, 32310, Chihuahua, Mexico \\ ${ }^{b}$ Facultad de Ingeniería Mochis, Universidad Autónoma de Sinaloa, Prol. Angel Flores y Fuente de \\ Poseidón, S/N, 81223, Los Mochis, Sinaloa, México \\ ${ }^{c}$ Universidad Tecnológica de Chihuahua Sur, Carr. Chihuahua a Aldama km. 3, S/N, 31313, Chihuahua, \\ Chihuahua, México \\ ${ }^{d}$ Facultad de Ingeniería, Universidad Autónoma de Chihuahua - UACH, Circuito No. 1, Nuevo \\ Campus Universitario, CP 31125, Chihuahua, Chihuahua, México \\ e Laboratorio Nacional de Nanotecnología, Centro de Investigación en Materiales Avanzados - CIMAV, \\ Miguel de Cervantes No. 120, 31136, Chihuahua, Chihuahua, México
}

Received: October 31, 2016; Accepted: November 28, 2016

\begin{abstract}
Equiatomic AlCoNi alloy matrix were reinforced by the dispersion of $\mathrm{SiC}$ nanoparticles ( $\mathrm{SiCnp}$ ) using the mechanical alloying process. The metallic powders were milled for 10,20 and $30 \mathrm{~h}$ and sintered at $1200{ }^{\circ} \mathrm{C}$ under vacuum. Through particle size distribution, X-ray diffraction and scanning electron microscopy investigations, the mechanically alloyed powders for $10 \mathrm{~h}$ were selected to be reinforced with SiCnp (2.5, 5 and $10 \mathrm{wt. \%})$. The microstructural features, and improvement in microhardness and porosity of sintered $\mathrm{AlCoNi}-\mathrm{SiC}$ composites were investigated as a function of SiCnp content. Microhardness Vickers test showed that the enhanced microhardness of the AlCoNi-SiCnp composite could be attributed to the decrease of porosity in comparison to the AlCoNi alloy.
\end{abstract}

Keywords: AlNiCo equiatomic system, composites, SiC nanoparticles, mechanical alloying, porosity

\section{Introduction}

Overlay coatings of the MCrAlY type $(\mathrm{M}=\mathrm{Ni}$, Co or $\mathrm{NiCo}$ ) are widely used for the protection of Ni-based superalloys from high-temperature degradation that gas turbine components are exposed during service. These coatings are commonly used in conjunction with a ceramic top coat (yttria-stabilized zirconia) to form thermal barrier coating system. The design of chemical compositions in overlay coatings has been changed to satisfice the increasing needs of mechanical properties, corrosion resistance of the overall system. Since 1965 the Cr content has decreased, while Al content has increased. Therefore, the study of a ternary Al-Co-Ni system is promising ${ }^{1,2}$. Concerning to chemical composition, it has been reported that multi-principal element alloys in equiatomic ratios can achieved superior physical and mechanical properties as high thermal stability and corrosion resistance ${ }^{3}$.

In the other hand, metallic materials with nanometric grain sizes can attain superior mechanical properties than those with coarse grained ${ }^{4-8}$. However, processing techniques that involve work hardening improve physical properties

* e-mail: francisco.baldenebro@uas.edu.mx as strength, typically achieved at the expense of ductility9. Several strategies have been developed to improve strength without sacrifice ductility in advanced metallic materials, mainly by the manipulation of microstructure, including the formation of a bimodal $/$ multimodal grain size distribution ${ }^{10}$. The dispersion of nano-sized ceramic particles into a metal matrix leads to the formation of metal matrix composites (MMC) $)^{11,12}$ for high-performance applications, due to their attractive physical and mechanical properties ${ }^{13}$ such as high strength, elastic modulus and thermal stability. In order to avoid the failure of MMC, the use of fine ceramic particles as reinforcement is preferred ${ }^{14}$. It has been reported that dispersion of ceramic particles are effective in strengthening metal matrix due to avoid the migration of dislocations and grain boundaries ${ }^{15}$. A decrease of the ceramic particle size from micrometric to nanometric scale leads to a superior improvement in the hardening of composite, but the tendency of particle agglomeration also increases.

Powder metallurgy (PM) is a method used for the synthesis of nanocrystalline MMC because it favors the homogeneous particles dispersion into matrix PM process could include mechanical alloying (MA) and mechanical milling (MM), followed by consolidation and sintering processes. Although, one disadvantage of conventional sintering process is the 
porosity that often leads to a detriment of mechanical properties as hardness and wear resistance ${ }^{16,17}$.

According to the proposed chemical designed of the AlCoNi alloy of this work, the increase of Al content could lead to the reduction of hardness and thermal stability. Hence, the incorporation of ceramic nano-sized particles as SiCnp to the equiatomic AlCoNi alloy is proposed in the present work to examine the microstructural evolution of equiatomic AlCoNi alloy reinforced with $\mathrm{SiC}$ nanoparticles by mechanical alloying and conventional sintering, as well as determine the influence of SiCnp addition on the porosity and microhardness.

\section{Experimental}

Elemental pure powders of $\mathrm{Al}$, Co and $\mathrm{Ni}$ (all pass through 325-mesh, metal basis) supplied by Alfa Aesar with high purity (99.97, 99.5 and $99.8 \%$ in weight) were used as starting metallic materials to prepare an equiatomic $\mathrm{AlCoNi}$ alloy by mechanical milling process. The stoichiometric amounts of pure metal $\mathrm{Ni}$, Co and $\mathrm{Al}$ powders mixed in 1:1 atomic ratio were sealed in a hardened steel vial using hardened steel balls under argon atmosphere. Grinding media consisted of binary mixtures of two ball sizes $(13 \mathrm{~mm}$ and $11 \mathrm{~mm}$ in diameter). The milling times were 10,20 and $30 \mathrm{~h}$. The milling was performed on a SPEX 8000M high energy mill using a ball to powder mass ratio of 5:1. Two drops of methanol per gram of powder was added as a process control agent to inhibit the particle agglomeration. The particle size distribution of alloyed powders was measured using laser diffraction and scattering with a Mastersizer-2000 particle size analyzer and B.E.T. surface measurements have been performed on a gas chromatograph Perkin Elmer 2. X-ray diffraction (XRD) patterns were recorded in a Panalytical X'Pert PRO diffractometer with mean $\mathrm{Cu} \mathrm{K}$ radiation $(\lambda=0.15406 \mathrm{~nm})$ to examine the structural evolution. The morphological and microstructural features were characterized by scanning electron microscopy (SEM, JEOL JSM-7401F).

The milled powders were cold-compacted under $1.5 \mathrm{GPa}$ of pressure, using an uniaxial compaction in a hydraulic press. According to density measurements in green products, the pore density increased with the milling time, hence the powders milled for $10 \mathrm{~h}$ were selected to be reinforced with SiCnp and obtain bulk samples for microhardness examinations. Silicon carbide nanoparticles with a particle size less than $100 \mathrm{~nm}$ was used as reinforcement (see Figure 1). The dispersion of SiCnp (2.5, 5 and $10 \mathrm{wt} . \%)$ in the mechanically alloyed (MA'ed) AlCoNi powders was performed during the 2 last hours of the mechanical alloying process. The milled powder composites were cold-compacted (uniaxial pressure of $1.5 \mathrm{GPa}$ ), sealed in quartz tube under vacuum, and sintered at $1200^{\circ} \mathrm{C}$ for $3 \mathrm{~h}$, followed by room temperature air-cooling. The porosity measurement of sintered samples

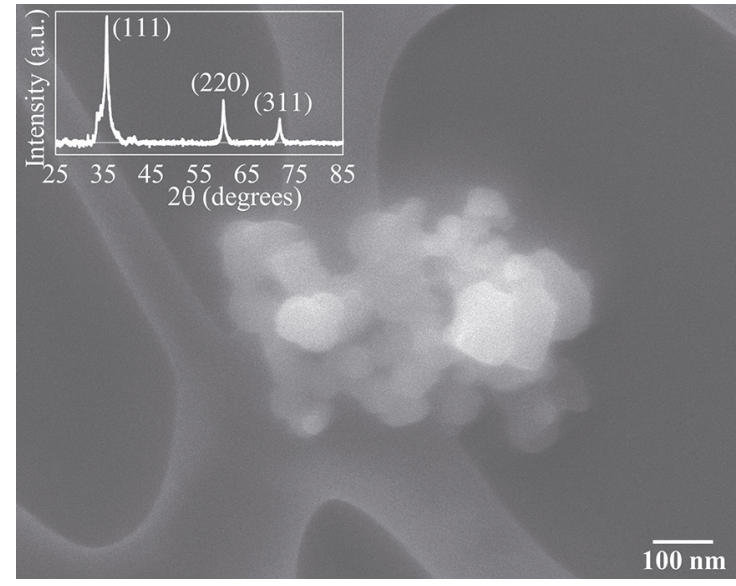

Figure 1: SEM micrographs of the $\mathrm{SiC}$ nanoparticles evidencing the particle diameter lower $100 \mathrm{~nm}$.

was carried out on the well-polished cross-section of the samples, using an optical microscope (Axio Scope A1) equipped with AxioVision SE64 software, and the hardness was measured by the Vickers microhardness test using a LM 300AT Leco MicroHardness tester under $200 \mathrm{~g}$ load and a dwell time of $10 \mathrm{~s}$.

\section{Results and Discussion}

Milling process has an important effect over the morphology of milled products. The intrinsic mechanical characteristics of powder as well as their volumetric fractions affect the surface characteristics of milled products. Starting materials and mechanically alloyed powders were analyzed by SEM technique. The as-received pure elemental powders exhibited different morphologies: nickel, angular; cobalt, irregular and aluminum, rounded. During MA the particles are cold welded forming larger particles at early stages of milling process. The agglomerated particles are exposed to a continuous process of fracture and cold welding, facilitating an atomic diffusion and allowing the MA process. Figures 2a-c show the AlCoNi powder particles after different milling times ( 10 , 20 and $30 \mathrm{~h}$, respectively). The homogeneous morphology of as-milled powders is achieved with the continuous competition between plastic deformation, agglomeration and size reduction. At the beginning of the mechanical alloying process, the powders are still soft enough to be agglomerated, and then the phenomenon of refinement and tightening of particles is undertaken as time passed, which indicates the equilibrium state of the process.

Figure $2 \mathrm{~d}$ shows the particle size distribution curves of MA'ed powders at different milling times. In the case of the sample with $10 \mathrm{~h}$ of mechanical alloying, the particle size distribution is a bimodal distribution with a mean particle size of $11.77 \mu \mathrm{m}$, while samples with 20 and $30 \mathrm{~h}$ exhibit a unimodal distribution, with a mean particle size of 15.85 

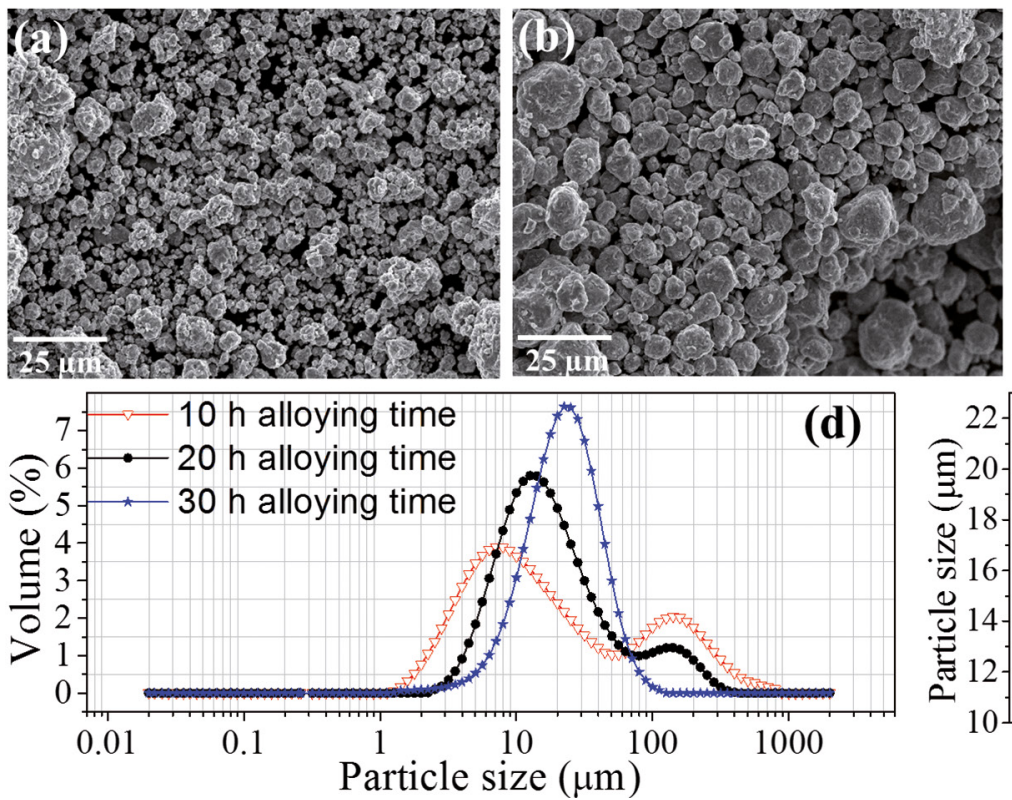
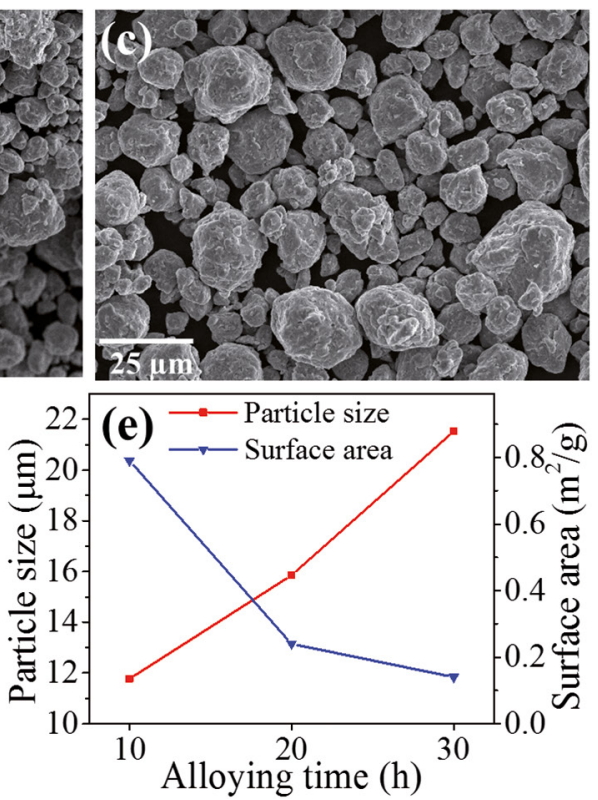

Figure 2: SEM micrographs of MA'ed AlCoNi powder alloy after (a) $10 \mathrm{~h}$, (b) $20 \mathrm{~h}$ and (c) $30 \mathrm{~h}$ of milling, (d) particle size distribution curves and (e) mean particle size and surface area.

and $21.53 \mu \mathrm{m}$, respectively. This is consistent with the results of surface area measurement (Figure 2e): 0.79, 0.24 and $0.14 \mathrm{~m}^{2} / \mathrm{g}$ for the samples milled during 10,20 and 30 $\mathrm{h}$, respectively. A reduction of the particle size is expected for longer alloying time. However, an opposite effect is observed, this could be due to the high ductility, stability and structure of the decagonal phase of the system Ni-Co$\mathrm{Al}^{18-23}$, in addition to the forming a bimodal/multimodal grain size distribution, that improves the ductility of the nanostructured materials ${ }^{24}$.

During mechanical alloying process, the continuous effect of cold welding and fracture produce the typical lamellar microstructure observed in MA'ed powders of Figure 3a. A dark phase with a chemical composition near to equiatomic molar ratio and a bright Co-rich phase were identified by EDS-SEM analyses, the results can be seen in Figure 3c.

After the sintering process, the lamellar microstructure disappeared while two distinguishable phases (Figure 3b) with internal pores are observed. Through EDS-SEM analyses was determined that the sintered microstructure is composed of a gray continuous phase with a chemical composition close to the equiatomic ratio, and a bright phase with low aluminum content, indicated in the Figure $3 \mathrm{~b}$ as zone D.

Structural changes of MA'ed AlCoNi powders were examined by XRD technique as a function of milling time (Figure 4). In the XRD pattern of $0 \mathrm{~h}$ (mixture) the sharp characteristic reflections corresponding to pure elements $\mathrm{Ni}$ $(\mathrm{FCC}, \mathrm{a}=0.352 \mathrm{~nm}), \mathrm{Co}(\mathrm{HCP}, \mathrm{a}=0.250$ and $\mathrm{c}=0.407 \mathrm{~nm})$ and $\mathrm{Al}(\mathrm{FCC}, \mathrm{a}=0.286 \mathrm{~nm})$ are observed. In the diffraction pattern corresponding to $10 \mathrm{~h}$ of milling, characteristic peaks of starting materials disappeared, while a BCC phase

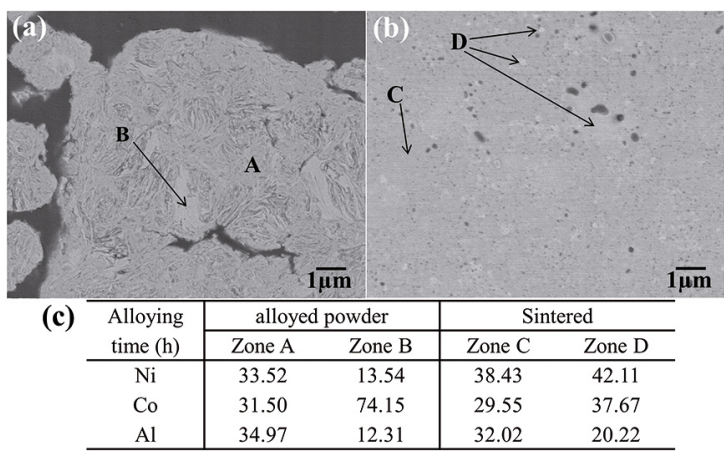

Figure 3: Backscattered electron SEM micrographs of AlCoNi samples: (a) cross-section powder with $10 \mathrm{~h}$ of milling and (b) sintered at $1200^{\circ} \mathrm{C}$, as well as (c) EDS-SEM analysis.

was formed $(\mathrm{a}=0.287 \mathrm{~nm})$. After 20 and $30 \mathrm{~h}$ of milling, the diffraction peak intensity decreases and peak width increases suggesting the decrease of crystallite size, without considerable changes in the phase composition. Substantial reduction in the crystallite size of $\mathrm{BCC}$ phase compared to the elemental microcrystalline powders is observed. Further milling results in a reduction of the crystallite size (from 6 to $4.2 \mathrm{~nm}$ ) and an increase of the microstrain (1.5 to $2.25 \%$ ), these measurements were performed using the Scherrer's formula and the plotted results are displayed in Figure 4b.

The Figure 5 shows the X-ray diffraction patterns of bulk AlCoNi-SiCnp composite samples as a function of the SiCnp content (0, 2.5, 5 and $10 \mathrm{wt} . \%)$. In the XRD patterns of the AlCoNi alloy, the main diffraction peaks correspond to a FCC phase $(\mathrm{a}=0.369 \mathrm{~nm})$ which intensity decrease with the addition of SiCnp and tend to disappeared at the higher SiCnp content (10 wt.\%). In the other hand, the 


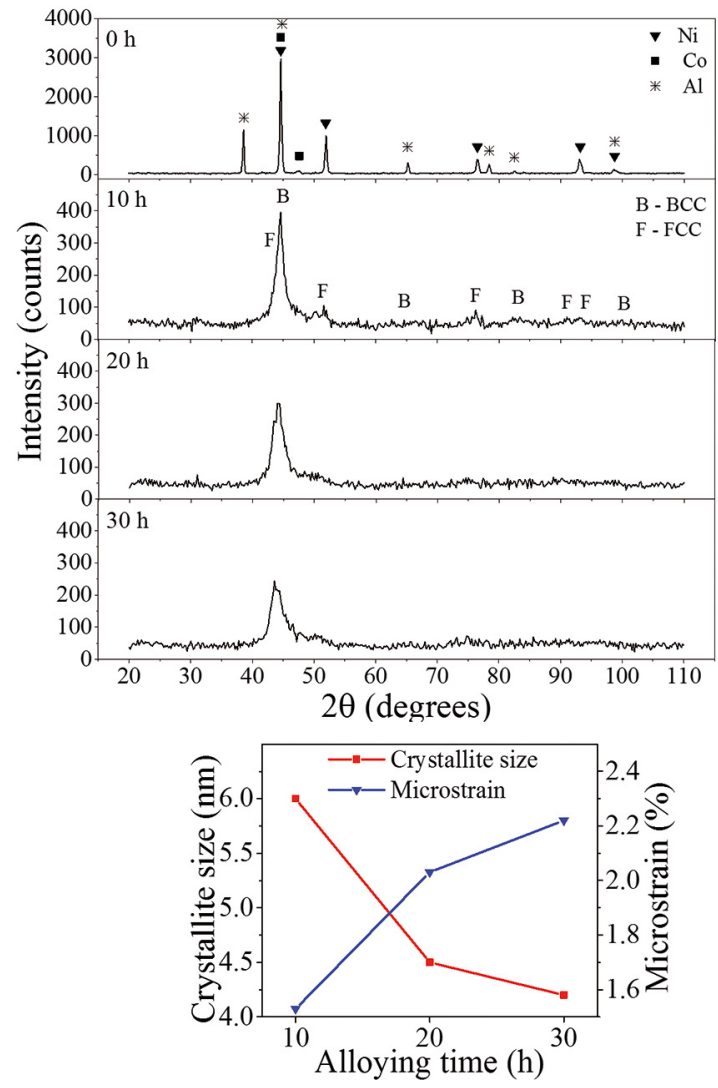

Figure 4: (a) XRD patterns of AlCoNi powder and (b) crystallite size and lattice deformation as a function of alloying time.

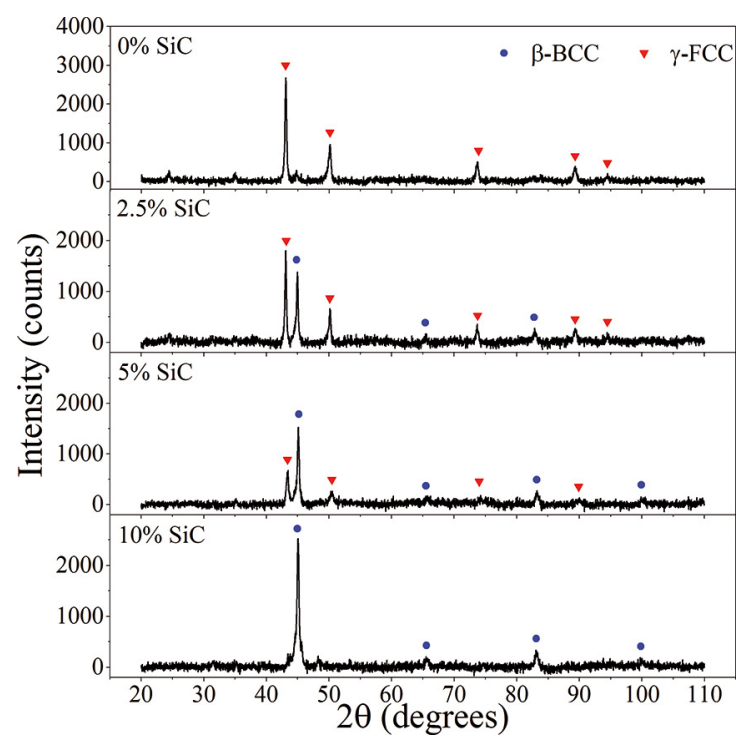

Figure 5: XRD patterns of sintered composite AlCoNi-SiCnp samples as a function of SiCnp content.

addition of SiCnp promotes the formation of a BCC phase since the lower content (2.5 wt.\%). Lattice parameter and crystallite size information of sintered composites samples are reported in Table 1. The crystallite size refinement and
Table 1: Structural characteristics of the sintered samples AlCoNi alloy reinforced with $\mathrm{SiC}$ nanoparticles.

\begin{tabular}{|c|c|c|c|}
\hline $\begin{array}{l}\text { Reinforced } \\
\text { sample }\end{array}$ & Phase & $\begin{array}{l}\text { Crystalline size } \\
\text { (nm) }\end{array}$ & $\begin{array}{l}\text { Lattice parameter } \\
\qquad(\mathrm{nm})\end{array}$ \\
\hline $0 \% \mathrm{SiC}$ & FCC & 55.83 & 0.369 \\
\hline \multirow{2}{*}{$2.5 \% \mathrm{SiC}$} & FCC & 53.46 & 0.363 \\
\hline & $\mathrm{BCC}$ & 53.24 & 0.284 \\
\hline \multirow{2}{*}{$5 \% \mathrm{SiC}$} & FCC & 52.78 & 0.361 \\
\hline & $\mathrm{BCC}$ & 52.61 & 0.284 \\
\hline $10 \% \mathrm{SiC}$ & $\mathrm{BCC}$ & 52.28 & 0.283 \\
\hline
\end{tabular}

lattice parameter reduction is presented for the both phases as a function of the SiCnp content.

The equilibrium microstructure as well as the chemical composition and distribution phases of sintered samples were investigated by SEM. Representative microstructure of the sintered samples with different percentages of $\mathrm{SiC}$ are shown in Figure 6. The Figure 6a shows the characteristic microporous microstructure of mechanically alloyed and sintered AlCoNi alloy. Elemental distribution obtained by SEM/EDS analyses revealed that after the sintering process the alloying elements are not homogeneously distributed (see Figure 6b-d). The elements tend to be concentrated in preferential regions and crystallizing new phases, which have different chemical composition (see Table 2). The consolidated specimens present two main phases, a continuous dark region (A) and a discontinuous bright region (B) and also dark rounded precipitates $(\mathrm{C})$. The phase $\mathrm{A}$ has a chemical composition close to the equiatomic ratio. The bright phase has a lower Al content (Figure 6a). The same two phases were identified in the reinforced AlCoNi specimens (Figure6b-d), presenting a significant decrease of aluminum content. The dark precipitates have a high aluminum and oxygen content, suggesting the formation of aluminum oxide. Also, it can be observed a higher porosity content in the unreinforced alloy compared to SiCnp-reinforced specimens but with a much finer dark precipitates microstructure.

Investigation of the reinforced consolidated specimens via SEM/EDS mapping (Figure 7) confirmed a higher aluminum and oxygen content in the dark precipitates, but the presence of $\mathrm{SiC}$ nanoparticles could not be identified by this way, which explains that homogeneous distribution of SiCnp could be reached by the mechanical alloying process avoiding the particles agglomeration.

The reinforced alloys exhibit high hardness that varies widely according to the contents of the reinforcing elements, so they it was interesting to evaluate the hardness of an equiatomic alloy with the addition of different $\mathrm{SiC}$ nanoparticles content. Vickers microhardness tests is one of the most simple and easiest techniques to find the tendency of mechanical properties of the studied alloys regarding to chemical composition. The obtained values of Vickers microhardness are presented in Figure 8, which indicate that 


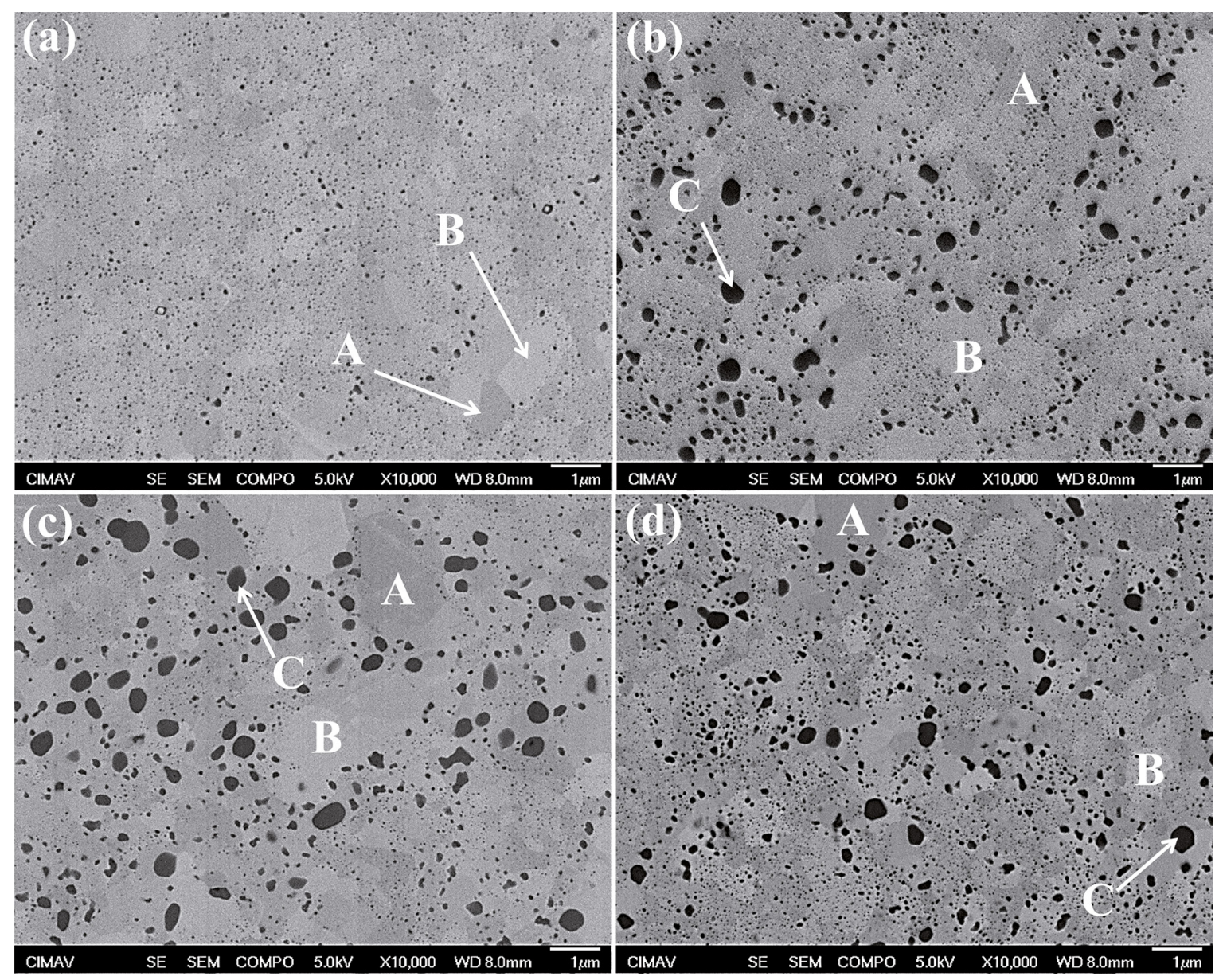

Figure 6: Backscattered electron SEM micrographs of the sintered samples AlCoNi: (a) 0, (b) 2.5, (c) 5.0 and (d) 10 wt.\% SiC.

Table 2: Chemical composition of phases identified on sintered samples determined by an EDS-SEM analysis (at.\%).

\begin{tabular}{lccccc}
\hline \multirow{2}{*}{ Alloying time (h) } & \multicolumn{2}{c}{ NiCoAl } & \multicolumn{3}{c}{ NiCoAl - 5.0\% SiC } \\
& Zone A & Zone B & Zone A & Zone B & Zone C \\
\hline $\mathrm{Ni}$ & 34.71 & 34.86 & 31.56 & 31.32 & 7.09 \\
$\mathrm{Co}$ & 30.66 & 34.34 & 31.07 & 31.28 & 6.49 \\
$\mathrm{Al}$ & 34.63 & 30.80 & 28.69 & 24.92 & 35.26 \\
$\mathrm{Si}$ & & 4.45 & 6.36 & 2.03 \\
$\mathrm{C}$ & & 4.23 & 6.12 & 1.94 \\
$\mathrm{O}$ & & & & 47.19 \\
\hline
\end{tabular}

the reinforced $\mathrm{AlCoNi}$ alloy exhibits an increase of hardness with the SiC nanoparticles content: 64, 101 and $192 \mathrm{HV}$ for $2.5,5$ and $10 \mathrm{wt} . \%$ SiCnp, respectively.

Any metal powder absorbs gases and water vapor from the atmosphere during storage. This adsorption can lead to the formation of pores during compaction and oxides during sintering at high temperatures, affecting the mechanical performance of bulk material. In the present study this inconvenience is diminished. The increase of SiCnp addition is proportional to the increase of microhardness and reduction of porosity by conventional sintering process. However, future investigations must be conducted to study in detail and understand the chemical reaction of SiCnp with the AlCoNi matrix and the effect in the porosity.

\section{Conclusions}

A set of reinforced AlCoNi-SiCnp composites were prepared by mechanical alloying with subsequent sintering under vacuum. The effects of $\mathrm{SiC}$ nanoparticles addition on 


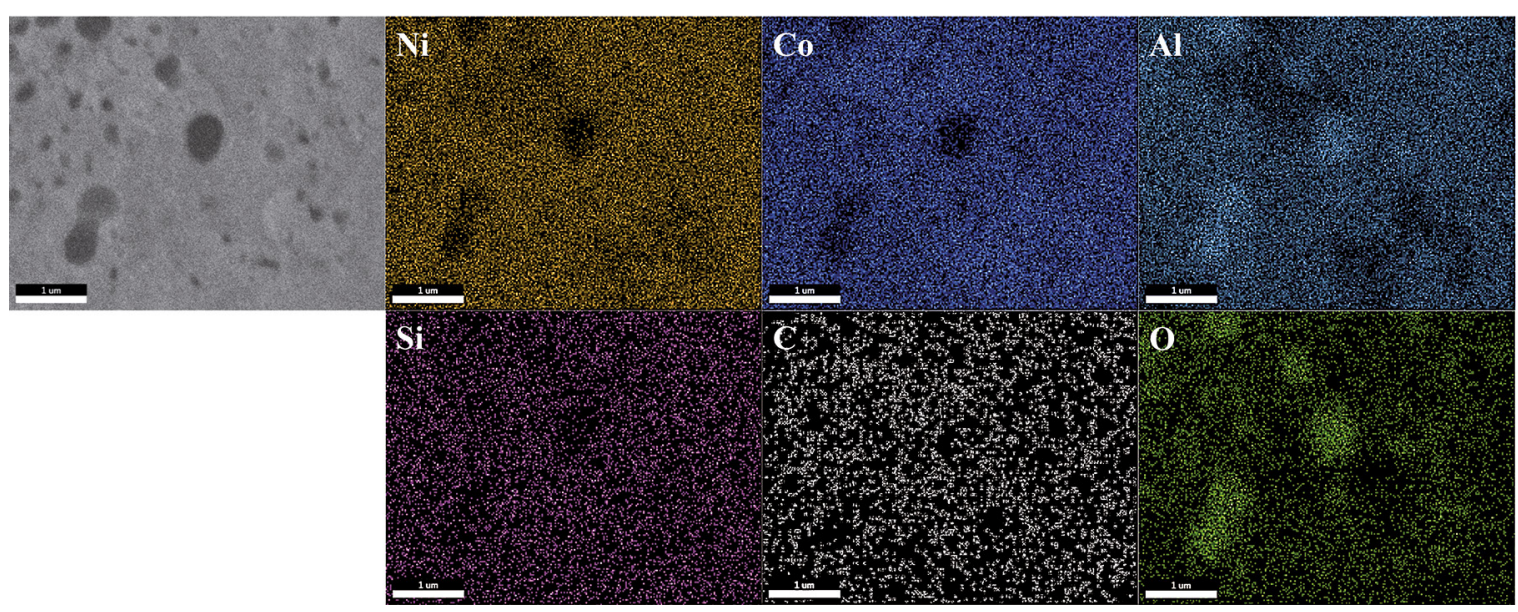

Figure 7: SEM-EDS mappings of 5\% SiC reinforced AlCoNi sample after sintering.

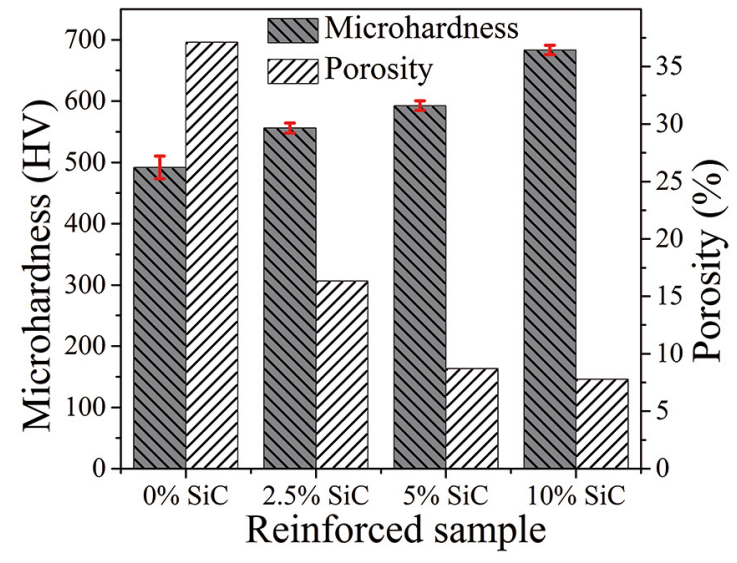

Figure 8: Microhardness and porosity of the sintered products

the microstructure and microhardness of the equiatomic AlCoNi alloy were investigated. Based on the obtained results the following conclusions can be made:

1. Incorporation of $\mathrm{SiC}$ nanoparticles into the $\mathrm{AlCoNi}$ powder alloy by PM confirmed that this technique is an excellent route for the dispersion of ceramic particles into metal matrix.

2. The presence of a mixture of simple nanocrystalline BCC and FCC phases in the equiatomic powder alloy processed by mechanical alloying was observed.

3. SEM studies revealed a microporous microstructure for the sintered AlCoNi alloy, whereas a reduction in pores density was observed for samples reinforced AlCoNi-SiCnp composites.

4. The presence of aluminum oxide in sintered AlCoNiSiCnp samples was observed. In addition, the volume fraction of aluminum oxide was increased with the SiCnp content. It suggests that the addition of SiCnp is involved in the formation of the aluminum oxide during sintering process.
5. The addition of $\mathrm{SiC}$ nanoparticles improved the microhardness of the AlCoNi alloy. Hardening mechanism of grain refinement is attributed to the mechanical alloying effect, while the reduction of porosity comprises the chemical reaction of SiCnp with the metal matrix and also promotes the formation of harder aluminum oxide precipitates.

\section{Acknowledgments}

The authors gratefully acknowledge to W. AntunezFlores, K. Campos-Venegas, E. Guerrero-Lestarjette, O. Solis-Canto and C.E. Ornelas-Gutiérrez for their technical assistance.

\section{References}

1. Liu XL, Lindwall G, Gheno T, Liu ZK. Thermodynamic modeling of $\mathrm{Al}-\mathrm{Co}-\mathrm{Cr}, \mathrm{Al}-\mathrm{Co}-\mathrm{Ni}, \mathrm{Co}-\mathrm{Cr}-\mathrm{Ni}$ ternary systems towards a description for $\mathrm{Al}-\mathrm{Co}-\mathrm{Cr}-\mathrm{Ni}$. Calphad. 2016;52:125-142.

2. Pomeroy MJ. Coatings for gas turbine materials and long term stability issues. Materials \& Design. 2005;26(3):223-231.

3. Murty BS, Yeh JW, Ranganathan S. A Brief History of Alloys and the Birth of High-Entropy Alloys. In: Murty BS, Yeh JW, Ranganathan S. High Entropy Alloys. Chapter 1. Oxford: Butterworth-Heinemann; 2014. p. 1-12.

4. Zhao S, Meng C, Mao F, Hu W, Gottstein G. Influence of severe plastic deformation on dynamic strain aging of ultrafine grained Al-Mg alloys. Acta Materialia. 2014;76:54-67.

5. Hu T, Ma K, Topping TD, Schoenung J, Lavernia EJ. Precipitation phenomena in an ultrafine-grained Al alloy. Acta Materialia. 2013;61(6):2163-2178.

6. Meng F, Rosalie JM, Singh A, Somekawa H, Tsuchiya K. Ultrafine grain formation in $\mathrm{Mg}-\mathrm{Zn}$ alloy by in situ precipitation during high-pressure torsion. Scripta Materialia. 2014;78-79:57-60. 
7. Hu T, Ma K, Topping T, Saller B, Yousefiani A, Schoenung J, et al. Improving the tensile ductility and uniform elongation of high-strength ultrafine-grained $\mathrm{Al}$ alloys by lowering the grain boundary misorientation angle. Scripta Materialia. 2014;78-79:25-28

8. Zhang S, Hu W, Berghammer R, Gottstein G. Microstructure evolution and deformation behavior of ultrafine-grained Al-Zn-Mg alloys with fine $\eta^{\prime}$ precipitates. Acta Materialia. 2010;58(20):6695-6705.

9. Vogt R, Zhang Z, Huskins E, Ahn B, Nutt S, Ramesh K, et al. High strain rate deformation and resultant damage mechanisms in ultrafine-grained aluminum matrix composites. Materials Science and Engineering: A. 2010;527(21-22):5990-5996.

10. Wang YM, Ma E. Three strategies to achieve uniform tensile deformation in a nanostructured metal. Acta Materialia. 2004;52(6):1699-1709.

11. Abdoli H, Salahi E, Farnoush H, Pourazrang K. Evolutions during synthesis of Al-AlN-nanostructured composite powder by mechanical alloying. Journal of Alloys and Compounds. 2008;461(1-2):166-172.

12. Bathula S, Anandani R, Dhar A, Srivastava A. Microstructural features and mechanical properties of Al 5083/SiCp metal matrix nanocomposites produced by high energy ball milling and spark plasma sintering. Materials Science and Engineering: A. 2012;545:97-102.

13. Kaneko S, Murakami K, Sakai T. Effect of the extrusion conditions on microstructure evolution of the extruded Al-Mg-Si-Cu alloy rods. Materials Science and Engineering: A. 2009;500(1-2):8-15.

14. Li M, Zhai H, Huang Z, Liu X, Zhou Y, Li S, et al. Tensile behavior and strengthening mechanism in ultrafine $\mathrm{TiC}_{0.5}$ particle reinforced $\mathrm{Cu}-\mathrm{Al}$ matrix composites. Journal of Alloys and Compounds. 2015;628:186-194.
15. Mazahery A, Shabani MO. Plasticity and microstructure of A356 matrix nano composites. Journal of King Saud University Engineering Sciences. 2013;25(1):41-48.

16. Tan MJ, Zhang X. Powder metal matrix composites: selection and processing. Materials Science and Engineering: A. 1998;224(1):80-85.

17. Chawla N, Deng X. Microstructure and mechanical behavior of porous sintered steels. Materials Science and Engineering A. 2005;390(1-2):98-112.

18. Grushko B, Holland-Moritz D. Quasicrystals and related structures in Al-Ni-Co. Journal of Alloys and Compounds. 1997;262-263:350-355.

19. Edagawa K, Tamaru H, Yamaguchi S, Suzuki K, Takeuchi S. Ordered and disordered phases in Al-Ni-Co decagonal quasicrystals. Physical Review B. 1994;50(17):12413-12419.

20. Baumgarte A, Schreuer J, Estermann MA, Steurer W. X-ray diffraction study of decaprismatic Al-Co-Ni crystals as a function of composition and temperature. Philosophical Magazine A. 1997;75(6):1665-1675.

21. Steurer W, Haibach T, Zhang B, Kek S, Lück R. The structure of decagonal $\mathrm{Al}_{70} \mathrm{Ni}_{15} \mathrm{Co}_{15}$. Acta Crystallographica Section $B$. 1993;49(1):661-675.

22. Würschum W, Troev T, Grushko B. Structural free volumes and systematics of positron lifetimes in quasicrystalline decagonal and adjacent crystalline phases of Al-Ni-Co, $\mathrm{Al}-\mathrm{Cu}-\mathrm{Co}$, and Al-Ni-Fe alloys. Physical Review B. 1995; 52(9):6411-6416.

23. Zhang B, Estermann M, Steurer W. The growth of decagonal Al-Co-Ni single crystals as a function of chemical composition. Journal of Materials Research. 1997;12(9):2274-2280.

24. Fan GJ, Choo H, Liaw PK, Lavernia EJ. Plastic deformation and fracture of ultrafine-grained Al-Mg alloys with a bimodal grain size distribution. Acta Materialia. 2006;54(7):1759-1766. 